\title{
RUBBLE MOUND BREAKWATER OVERTOPPING: ESTIMATION OF THE RELIABILITY OF A 3D NUMERICAL SIMULATION
}

\author{
Luca Cavallaro ${ }^{1}$, Fabio Dentale ${ }^{2}$, Giovanna Donnarumma ${ }^{3}$, Enrico Foti ${ }^{4}$, Rosaria E. \\ Musumeci ${ }^{5}$ and Eugenio Pugliese Carratelli ${ }^{6}$
}

\begin{abstract}
Until recently, physical models were the only way to investigate into the details of breakwaters behavior under wave attack. From the numerical point of view, the complexity of the fluid dynamic processes involved has so far hindered the direct application of Navier-Stokes equations within the armour blocks, due to the complex geometry and the presence of strongly non stationary flows, free boundaries and turbulence. In the present work the most recent CFD technology is used to provide a new and more reliable approach to the design analysis of breakwaters, especially in connection with run-up and overtopping. The solid structure is simulated within the numerical domain by overlapping individual virtual elements to form the empty spaces delimited by the blocks. Thus, by defining a fine computational grid, an adequate number of nodes is located within the interstices and a complete solution of the full hydrodynamic equations is carried out. In the work presented here the numerical simulations are carried out by integrating the three-dimensional Reynolds Average Navier-Stokes Equations coupled with the RNG turbulence model and a Volume of Fluid Method used to handle the dynamics of the free surface.

The aim of the present work is to investigate the reliability of this approach as a design tool. Two different breakwaters are considered, both located in Southern Sicily: one a typical quarry stone breakwater, another a more complex design incorporating a spill basin and an armoured layer made up by Coreloc $®$ blocks.
\end{abstract}

Keywords: rubble-mound breakwater; numerical simulation; RANS/VOF; overtopping

\section{INTRODUCTION AND BACKGROUND}

Until recently physical tank models, and formulas derived from them, have been the only way to evaluate the effects of wave actions on breakwaters. In the last ten years, advances of Computational Fluid Dynamics (CFD) in free surface problems have lead to a decisive step forward, to the point that nowadays the design of any important coastal structure will necessarily include $2 \mathrm{D}$ or even $3 \mathrm{D}$ simulation of the flow around the structure, in place or in connection with laboratory experiments. The now practically standard practice involves the numerical integration of Reynolds Averaged NavierStokes (RANS/VOF) equations on a fixed grid, with one or more of the available turbulence models (K-eps, $\mathrm{K}-\omega, \mathrm{RNG}$ ) and a free surface tracking procedure - this latter generally based on the Volume of Fluid Method (Hirt and Nichols 1981).

These methods were developed by many authors. No exhaustive review of the literature in this field is possible, or indeed useful; however (Dentale et al. 2008) provided an extensive - if now somewhat outdated - analysis of the current methods, and it appears that the most commonly used code is COBRAS (COrnell BReaking waves And Structures), originally developed by at Cornell University (Lin and Liu 1998), (Liu and Al-Baana 2004). It was subsequently applied by Losada and his coworkers (e.g. Lara et al. 2006, Losada et al. 2008) who provided an extensive validation on many cases of engineering importance.

Tests with OTT code were carried out by Giarrusso et al. (2003). FLOW-3D by Flow Science (Chopakatla et al. 2008, Dentale et al. 2009, Li et al. 2004) has also been widely tested. More recently FLUENT (Fang et al. 2010), PHOENICS (Hafsia et al. 2008) and OpenFOAM (Javier et al. 2012) have also been also successfully used. Finally, in a few cases specially built codes have been applied, as for instance by Christensen (2006). SPH and similar particle methods are also being tested: Viccione at al. $(2011,2012)$ report some recent developments.

The design of rock mound breakwaters opens an entirely new class of problems, as it implies dealing with the flow within the interstices of the rock mound: the complexity of the fluid dynamics involved, which features strongly non stationary flow, momentum advection, free boundary and possibly turbulence and air-water interaction, all within a very complex geometry, has until recently hindered the direct application of Navier-Stokes integration. Current RANS/VOF practice deals with

\footnotetext{
${ }^{1}$ Dept of Civil Engineering, University of Messina, Icavallaro@ingegneria.unime.it, Messina, Italy

${ }^{2}$ MEDUS, Dept of Civil Engineering, University of Salerno, fdentale@unisa.it, Salerno, Italy

${ }^{3}$ MEDUS, Dept of Civil Engineering, University of Salerno, gdonnarumma@unisa.it, Salerno, Italy

${ }^{4}$ Dept of Civil and Environmental Engineering, University of Catania, efoti@dica.unict.it, Catania, Italy

${ }^{5}$ Dept of Civil and Environmental Engineering, University of Catania, rmusume@dica.unict.it, Catania, Italy

${ }^{6}$ MEDUS, Dept of Civil Engineering, University of Salerno, epc@unisa.it, Salerno, Italy
} 
this problem by considering the rock mound as a porous body and takes into account the influence of porosity by assuming that the flow within the rubble mound can be treated by the "porous media" approach, and therefore governed by the seepage flow equations (Darcy or Forchheimer, if the head loss is linear or quadratic respectively). In practice, an additional term is added to the equations to reproduce the interactions between the fluid and the inner flow paths by using homogeneous coefficients for the entire filtration domain; in some instances, an acceleration term is also introduced, leading to a Morison-like behaviour. Of course the relevant parameters have to be carefully calibrated with an ad hoc procedure on the basis of available experimental data. Such an approach was first reported in Hsu et al. (2002), later implemented in the COBRAS numerical code (i. e. Garcia et al. 2004, Gotoh et al. 2004, Greben et al. 2008, Karim and Tingsanchali 2006, Lara et al. 2006, Losada et al. 2008, Requejo et al. 2002).

It is easy to see that while the "seepage" assumption is physically sound for small armour units, it certainly fails for blocks of large size, when the Reynolds number of flow inside the paths is high. Besides, the stability of a single unit cannot be evaluated with the seepage flow, so the methods is limited to the estimation of global parameters such as overtopping or global stability, and does not seem to offer any perspective of future application to the all-important problem of evaluating armour unit size and shape. Thus, the designer of armour block structures is left with empirical formulas and model tests, with nothing in between.

Only recently serious attempts have been made to model the detailed hydrodynamics of block mound structures on the basis of their real geometry by using advanced digital techniques. Thus, by defining a fine computational grid, an adequate number of computational nodes is located within the interstices so that a complete solution of the full hydrodynamic equations is carried out including convective effects and, possibly, resolving the turbulence structure. Pioneering work with full simulation of the Flow Within the Armour Units (FWAU) work was carried out by Dentale et al. (2010) by using RANS-VOF; SPH (Smoothed Particle Hydrodynamics) was applied to this problem by Altomare et al. (2012), while an entirely new approach, involving both CFD techniques in the interstices and numerical solid mechanics in the block themselves, is being attempted by Xiang et al. (2012).

The aim of the present work is to report a real life experience which has been used a benchmark to investigate the reliability of FWAU as a design tool and particularly in connection with overtopping. A set of laboratory tests was specially carried out to compare experimental with computed results.

\section{STATEMENT OF PROBLEM}

A composite breakwater, with a complex geometry including a spill basin and an armoured layer made up by Coreloc $\AA$, is being designed for the protection of the industrial port in Gela (Sicily), as shown in Fig.1. In the following this section will be referred to as "Gela".

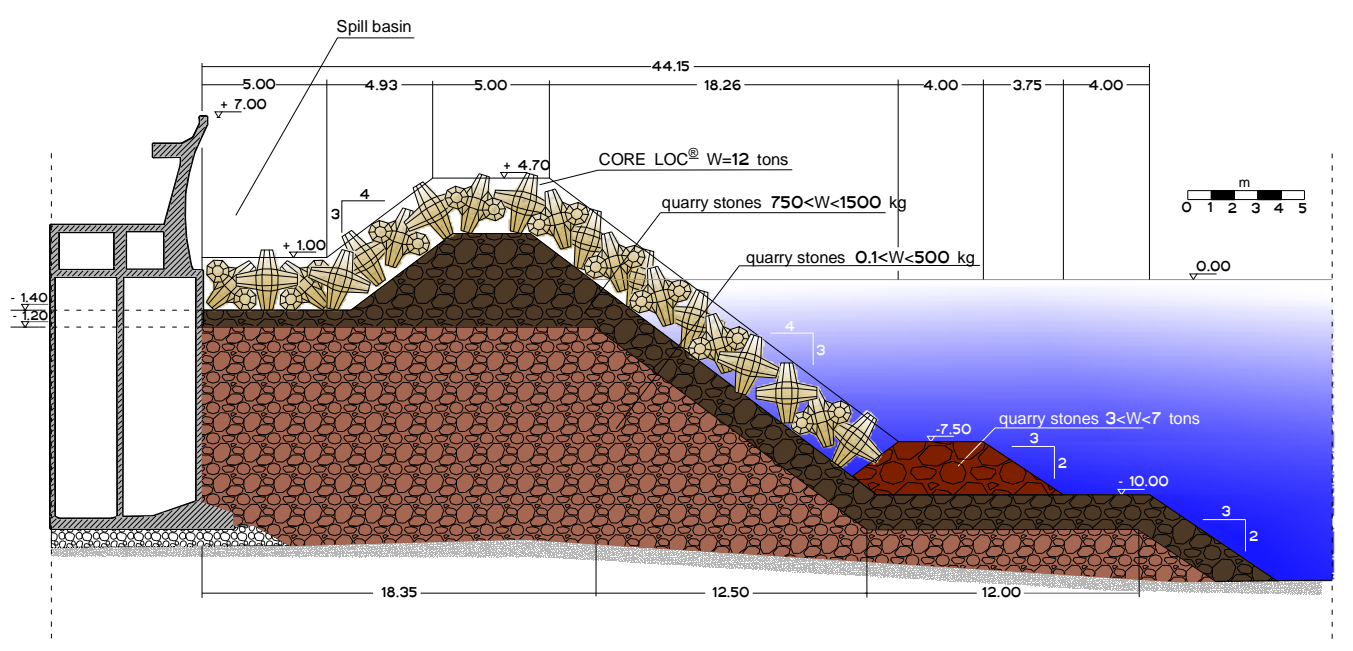

Figure 1. Port of Gela: Cross section of rubble mound breakwater 
As it can easily be seen, the presence of a spill basin makes the cross section entirely different from the standard shape taken as a reference for various empirical formulae. No experimental data is available on the overtopping, except for a single value deriving from model tests carried many years ago.

A further breakwater (in the following "Sant'Erasmo") is also being considered; a more conventional large quarry stone breakwater designed for the new port of Sant'Erasmo (Sicily) and illustrated in Fig. 2, has been the object of extensive laboratory tests and is taken in the following as a reference (La Rocca et al. 2010).

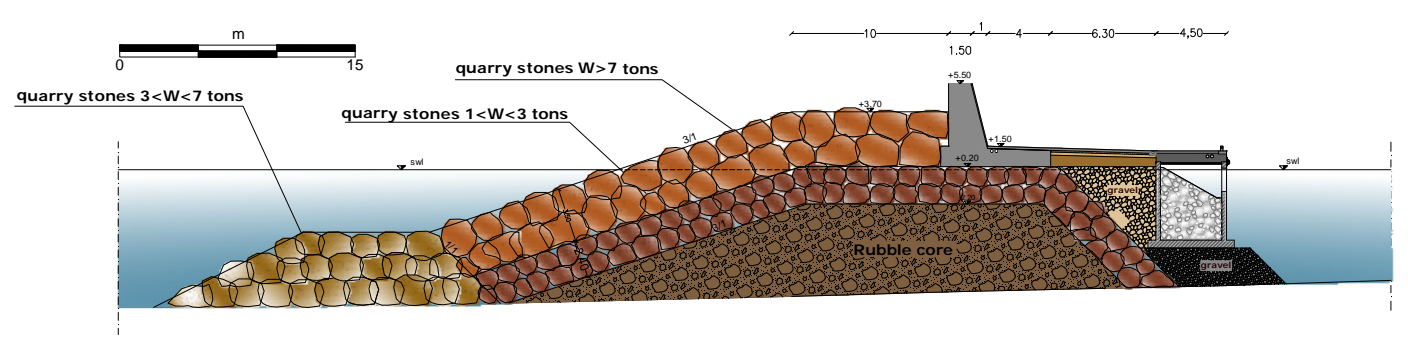

Figure 2. Port of Sant' Erasmo: Cross section of rubble mound breakwater

\section{METHODS: COMPUTATION OF FLOW WITHIN ARMOR UNITS}

As stated above, by making use of standard 3D CAD features it is now practically possible to represent the solid structure which interacts with the flow by overlapping individual elements, so as to create a numerical calculation domain within empty spaces between the blocks. Breakwaters, both submerged and emerged are numerically constructed by overlapping individual blocks under the conditions of gravity thus shaping the structure according to a real geometry, very much like in the case of real manufacturing or laboratory tests. Natural stone mounds are reproduced with a set of spheres, while a data base is available for artificial blocks such as the cube, the modified cube, the Antifer ${ }^{\mathbb{B}}$, the tetrapod, etc.

It is thus possible to evaluate the effect of the full hydrodynamic behaviour, including the convective terms and the effects of turbulence, which cannot be taken into account with the classical Darcy scheme, largely inadequate in such kind of situations.

Once the breakwaters geometry is defined, its geometric configuration is imported into the CFD system. All the results shown in the following were obtained with FLOW-3D ${ }^{\circledR}$; however also CHAM'S Phoenics $^{\circledR}$ and COBRAS were occasionally applied to verify and validate the results.

The simulations were carried out by integrating the Navier-Stokes equations in the complete form (3D), with a RNG turbulence model, and using a computational grid a two "nested" meshes, the finer one being located in the breakwater area, where the flow has to be computed within the interstices and therefore the hydrodynamics is more complex.

Fig. 3 and Fig. 4 show the numerical model of breakwater for Gela and Sant'Erasmo. Fig. 5 shows the general layout, while Fig. 6 provide an example of the computational detail.
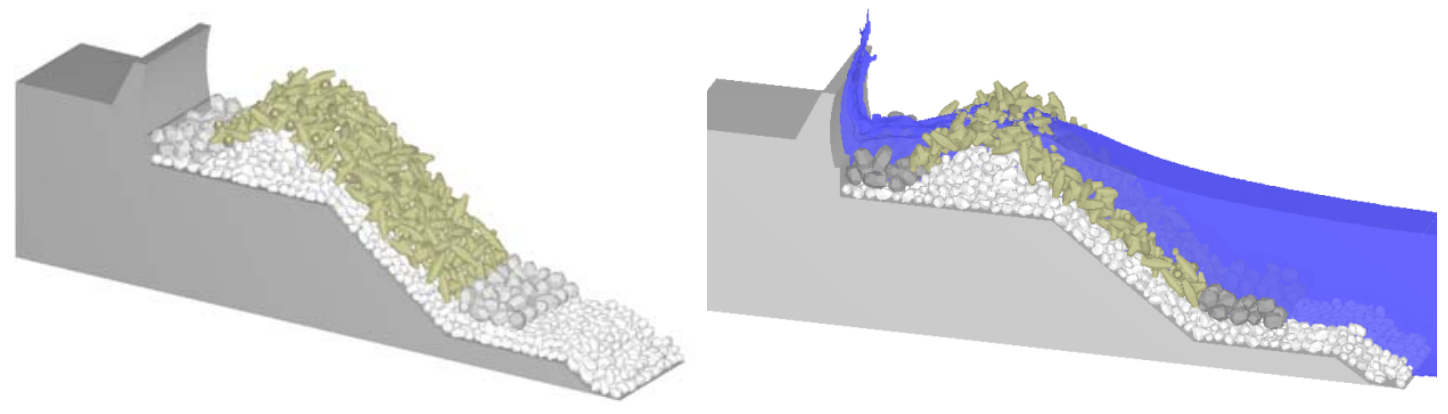

Figure 3. Numerical model of the breakwater (left) and results free surface evolution (right) - Port of Gela 


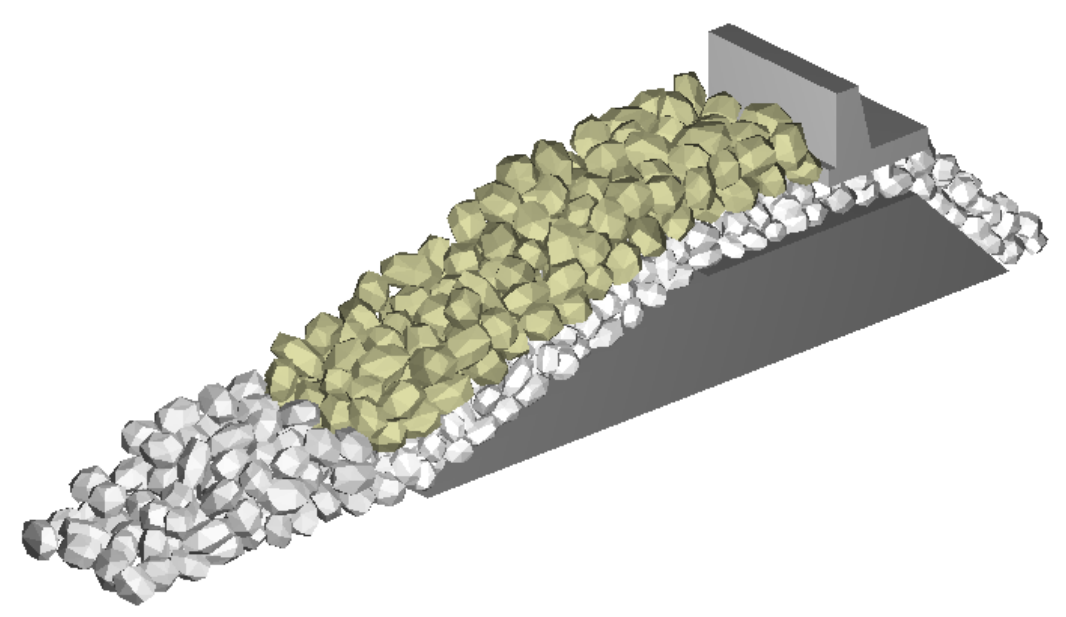

Figure 4. Numerical model of the breakwater - Port of Sant'Erasmo

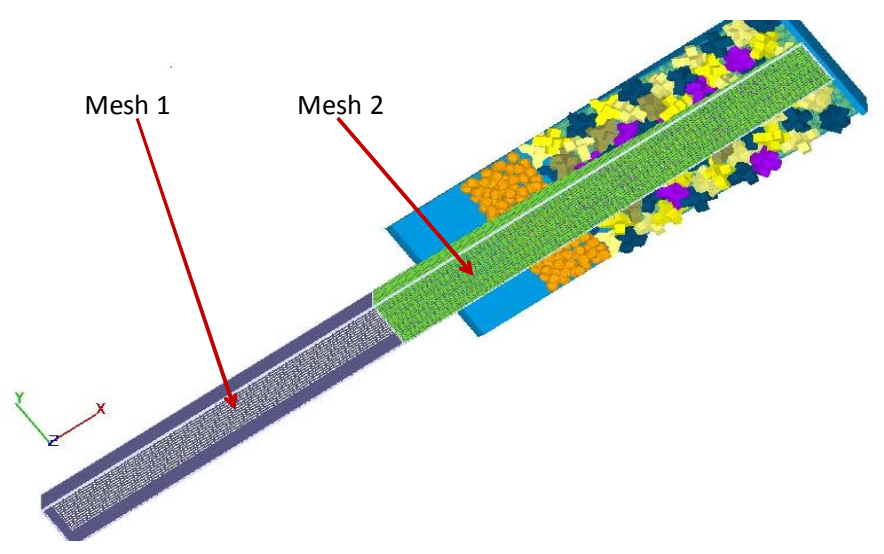

Figure 5. General layout

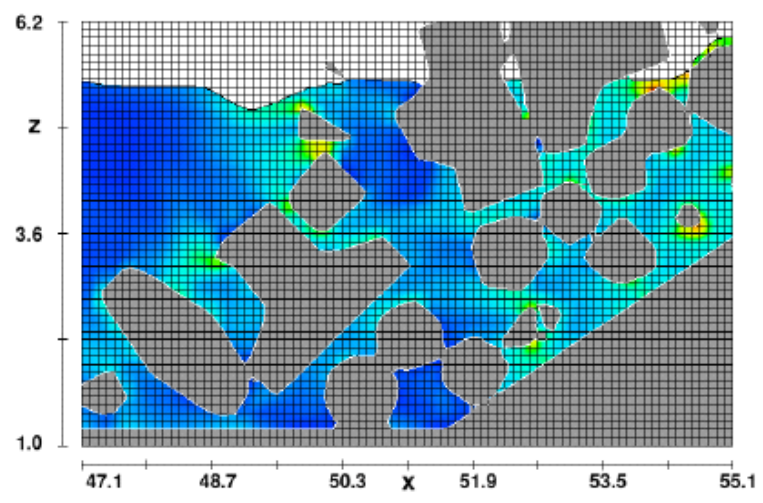

Figure 6. Example of the computational detail

The problem is computationally massive. After an appropriate convergence tests, the outer mesh for all the computations was chosen to be made up of 150.000 cells, $0.50 \times 0.20 \times 0.30 \mathrm{~m}$, while the local one was 2.025 .000 cells, $0.10 \times 0.10 \times 0.10 \mathrm{~m}$.

The velocity in a give point within the rock mound of course oscillates (Fig. 7), but typical values for Reynolds Number at the peak are about $10^{6}$, while the Strouhal number is about 0.1 . 


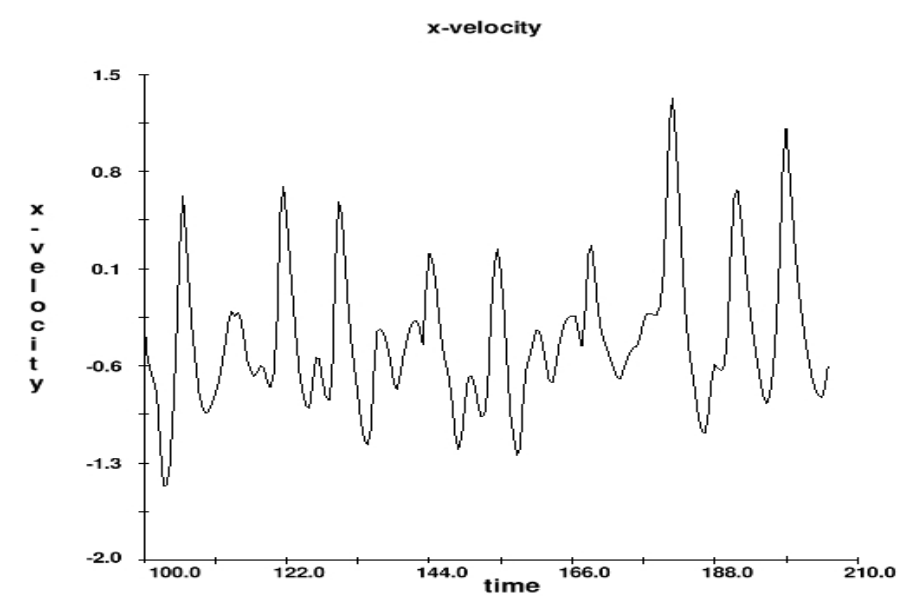

Figure 7. Velocity in a give point within the rock mound

\section{METHODS: EXPERIMENTAL TESTS}

The Sant'Erasmo experiments were carried out in the wave flume of the Hydraulic Laboratory of the University of Catania (Italy). The flume, with lateral transparent glass walls, is $18 \mathrm{~m}$ long, $3.60 \mathrm{~m}$ wide and $1.20 \mathrm{~m}$ deep. A flap-type wavemaker allows both regular and irregular wave series to be reproduced. Three resistive gauges were located in front of the structure in order to evaluate the wave reflection coefficients by means of the Goda and Suzuki (1976) method. Physical modelling was carried out by using a geometrically undistorted 1:80 scale with respect to the prototype and by guaranteeing Froude similarity.

Two different cross-sections and five wave conditions for each of them were tested. The main geometric characteristics of such sections are reported in Table 1.

\begin{tabular}{|c|c|c|}
\hline \multicolumn{3}{|c|}{ Table 1. Geometric characteristic of St Erasmo tests. } \\
Prototype scale
\end{tabular}

Table 2 shows, for each test, the wave significant height, the peak period, the reflection coefficient and the overtopping discharge.

Some limited experimental overtopping information is available for Gela since a few laboratory tests had been performed by the Estramed company (Italy) on 1:30 scale. The section selected for this study had been tested for two hydrodynamic condition: i) $\mathrm{Hs}=4 \mathrm{~m} \mathrm{Tp}=9.9 \mathrm{~s}$; ii) $\mathrm{Hs}=5.4 \mathrm{~m} \mathrm{Tp}=12.8 \mathrm{~s}$. Only the second condition produced an overtopping discharge.

\section{COMPARISON OF RESULTS}

The most relevant results of the tank tests (Qmeas), and of the RANS/VOF computations carried out with the full simulation of the flow among the blocks, as described in the previous paragraphs (QNumerical3D) are reported in Fig. 8, where $\mathrm{Q}^{*}$ and $\mathrm{R}^{*}$ are given by: 


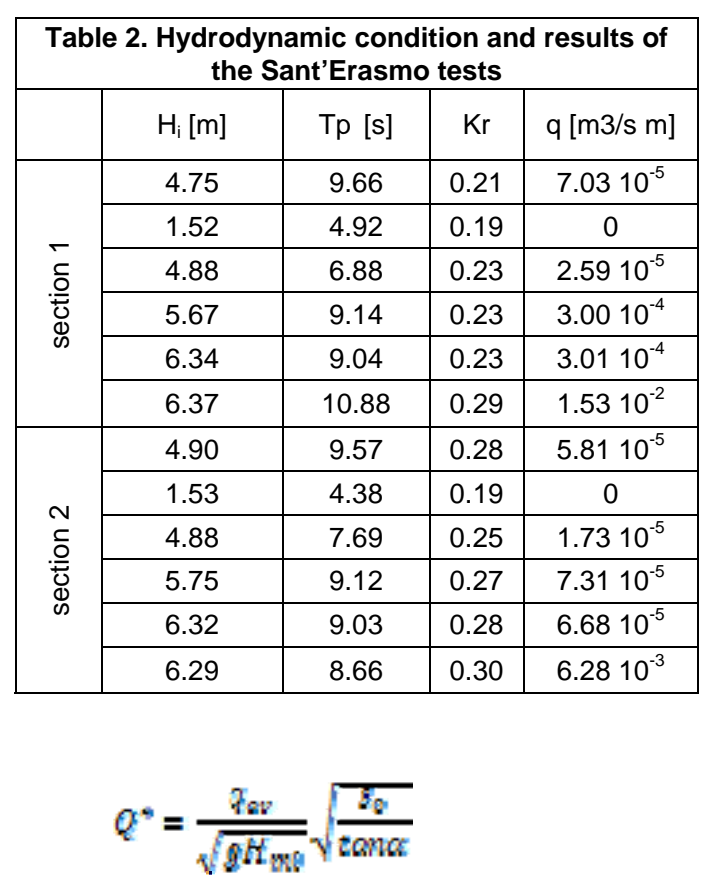

and

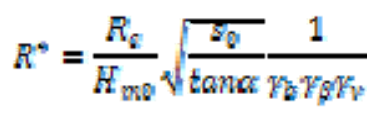

$\mathrm{R}_{\mathrm{c}}$ is the breakwater crest height; $\mathrm{H}_{\mathrm{m} 0}$ the wave significant height and $\mathrm{s}_{0}$ its slope; $\mathrm{q}_{\mathrm{ov}}$ the overtopping flow; tan $\alpha$ the armour slope; $\gamma_{b}, \gamma_{\beta}$ and $\gamma_{v}$ empirical parameters as in Van der Meer (1998). The value obtained by the latter formula are also reported in the same picture (Qemp).

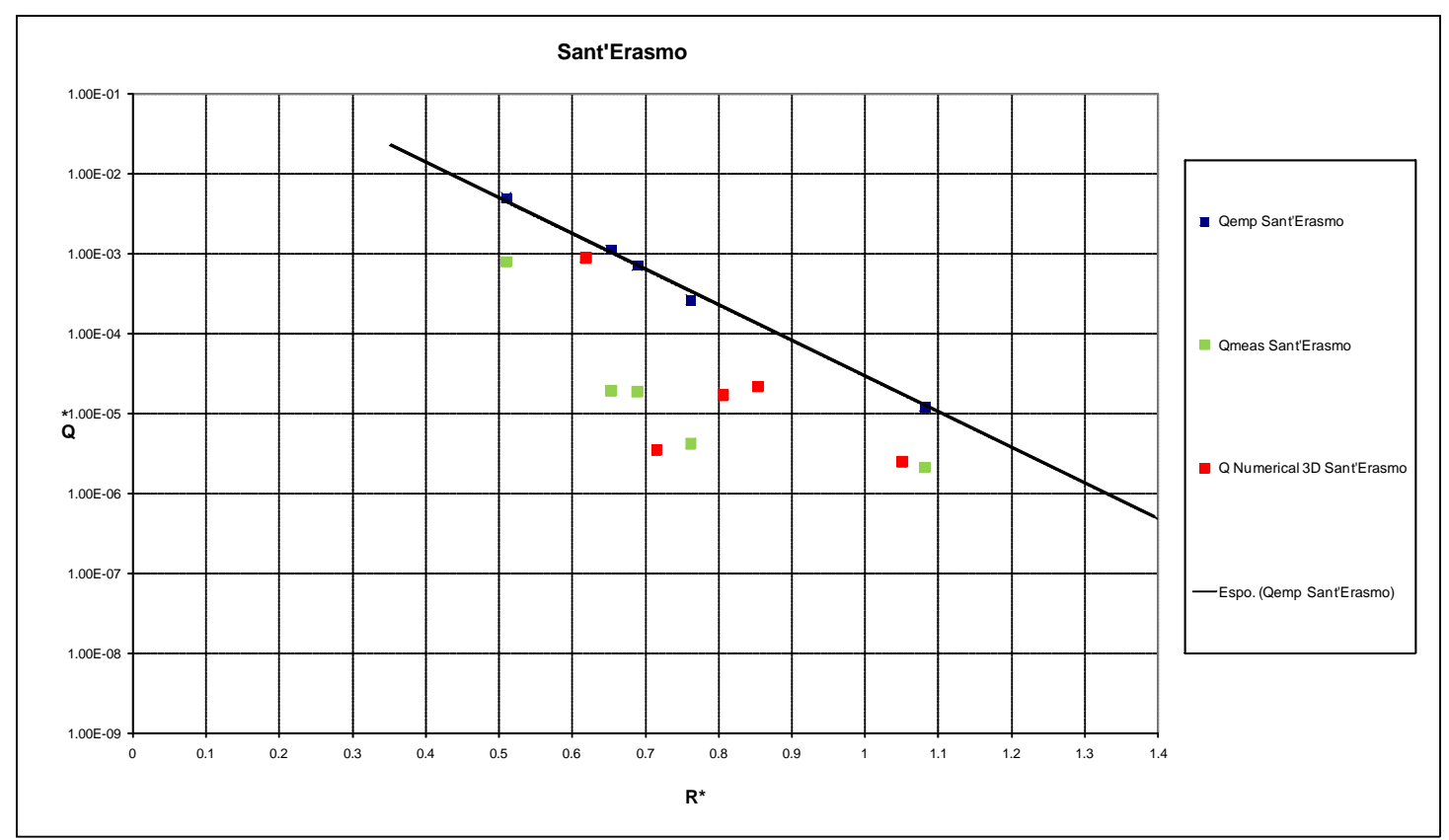

Figure 8. Experimental and numerical results - Sant'Erasmo

Within the limits of the usual approximation of this kind of experiments, the 3D RANS/VOF methods compare well with the tank test. It is worth remembering that - unlike seepage RANS/VOF the methods does not require any parameter calibration. 
The following Fig. 9 reports the same information for the Gela case study. Only one tank test result is available (Estramed), but in this case seepage RANS/VOF has also been considered (Q numerical porous media). This latter approach consistently underestimates the overtopping flow values.

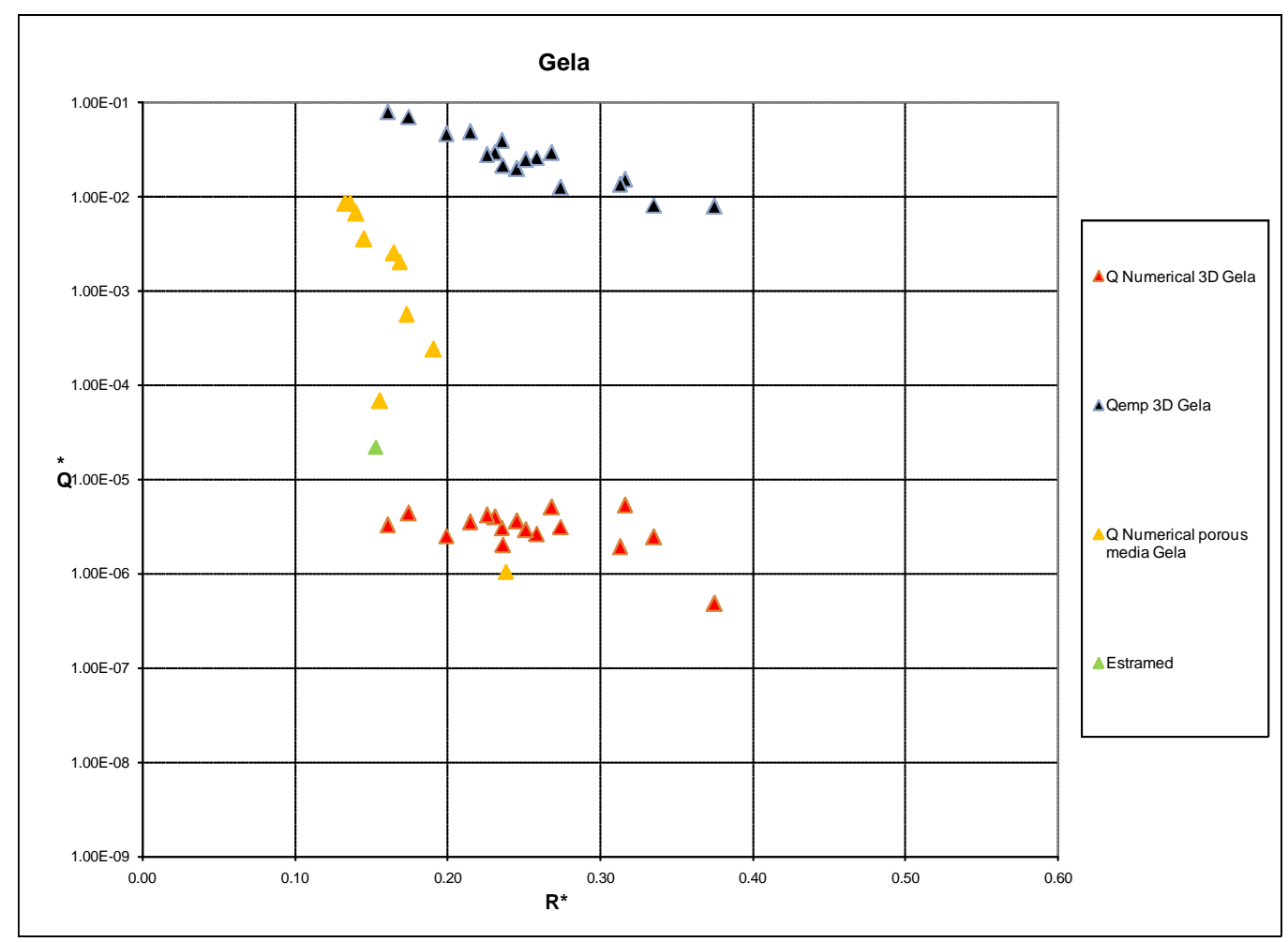

Figure 9. Experimental and numerical results - Gela

The results show a good agreement between the numerical simulation obtained with FLOW-3D ${ }^{\circledR}$ (QNumerical 3D Gela) and the experimental data (Extramed). It is also that: i) the presence of the spill channel between the crest of the rubble mound breakwater and the wave wall produces a relevant reduction of wave overtopping compare to a traditional cross-section without spill basin (Qemp 3D Gela); ii) the simulations performed with a porous media approach produce an overestimation of the overtopping discharges.

\section{CONCLUSION AND FURTHER WORK}

A real life overtopping problem with an unusual geometry (spilling basin) could not be properly treated with standard available formulae. Since direct experimental results were not available, an innovative RANS/VOF procedure was tested and calibrated against tank tests with a different geometry. The new, and more complex, technique produced better results than the traditional approach whereby the flow within the armour is computed with seepage flow approximation.

Results show that by using advanced digital techniques, rubble mound and block armour maritime structures can modelled on the basis of their real geometry, taking into account the hydrodynamic interactions with the wave motion: further developments might also eventually lead to evaluate the stability of the individual elements of the mound.

\section{REFERENCES}


Altomare, C., X.F. Gironella, A.J.F. Crespo, J.M. Domínguez, M. Gómez - Gesteira, and B.D. Rogers. 2012. Improved accuracy in modelling armoured breakwaters with SPH, 7th international SPHERIC workshop, Prato, Italy.

Chopakatla, S.C., T.C. Lippmann, and J.E. Richardson. 2008. Field verification of a computational fluid dynamics model for wave transformation and breaking in the surf zone, Journal of Waterway, Port, Coastal, and Ocean Engineering, 134-2, 71-81.

Christensen, E.D. 2006. Large eddy simulation of spilling and plunging breakers, Coastal Engineering, 53, 463-485.

Dentale, F., M. Monaco, and E. Pugliese Carratelli. 2008. A numerical assessment of scale effects on wave breaking modelling, 3rd SCACR International Short Course and Workshop on Applied Coastal Research, Lecce, Italy.

Dentale, F., E. Pugliese Carratelli, and S. Pane. 2009. Modellazione numerica del moto ondoso su barriere frangiflutti sommerse porose, Studi Costieri, 16, (In italian).

Dentale, F., S.D. Russo, E. Pugliese Carratelli, and S. Mascetti. 2010. A new numerical approach to study the wave motion within breakwaters and the armour stability, Marine technology reporter, 54, 34-37.

Dentale F., G. Donnarumma, and E. Pugliese Carratelli. 2012. Wave run up and reflection on tridimensional virtual breakwater, Journal of Hydrogeology \& Hydrologic Engineering (in press).

Fang, Z., L. Cheng, and N. Zhang. 2010. Development of 3-D Numerical Wave Tank and Applications on Comb-Type Breakwater, 29th International Conference on Ocean, Offshore and Arctic Engineering (OMAE2010), Shanghai, China.

Garcia, N., J.L. Lara, and I.J. Losada. 2004. 2-D numerical analysis of near-field flow at low-crested breakwaters, Coastal Engineering, 51(10), 991-1020.

Giarrusso, C.C., F. Dentale, and E. Pugliese Carratelli. 2003. On the stability of protected beaches, Sixth International Conference on Computer Modelling and Experimental Measurement of Seas and Coastal Regions, Coastal Engineering VI; Cadiz, Spain.

Goda Y., and Y. Suzuki. 1976. Estimation of incident and reflected waves in random wave experiments, Proceedings of 15th International Conference on Coastal Engineering, ASCE, Honolulu, Hawaii, 1, 828-845.

Gotoh, H., S. Shao, and T. Memita. 2004. SPH-LES Model for numerical investigation of wave interaction with partially immersed breakwater, Coastal Engineering Journal (JSCE), 46(1), 3963.

Greben, J., K. Cooper, I.M. Gledhill, and R. De Villiers. 2008. Numerical modeling of structures of dolosse and their interaction with waves, Technical report, CSIR, Pretoria, South Africa.

Hafsia Z., B.H. Mehdij, H. Lamloumi, K. Maalel, and R. Zgolli. 2008. Linear and nonlinear numerical wave generation in viscous fluid, Phoenics News.

Hirt, C.W., and B.D. Nichols. 1981. Volume of fluid (VOF) method for the dynamics of free boundaries, Journal Comp. Physics, 39, 201-225.

Hsu, T.J., T. Sakakiyama, and P.L.F. Liu. 2002. A numerical model for wave motions and turbulence flows in front of a composite breakwater, Coastal Engineering, 46, 25- 50.

Javier, L., J.L. Lara, P. Higuera, M. Maza, M. del Jesus, I.J. Losada, and G. Barajas. 2012. Forces induced on a vertical breakwater by incident oblique waves, 33rd International Conference on Coastal Engineering (ICCE), Santander, Spain.

Karim, M.F., K. Tanimoto, and P.D. Hieu. 2009. Modeling and simulation of wave transformation in porous structures using VOF based two-phase flow model, Applied Mathematical Modeling, 33, 343-360.

Karim, M.F., and T. Tingsanchali. 2006. A coupled numerical model for simulation of wave breaking and hydraulic performances of a composite seawall, Ocean Engineering, 33, 773-787.

La Rocca C., R.E. Musumeci, G. Paratore, and E. Foti. 2010. Application of computer vision techniques for the optimization of a rubble mound breakwater, L'Acqua, 2/2010, 53-68 (in italian).

Lara, J.L., N. Garcia, and I.J. Losada. 2006. RANS modeling applied to random wave interaction with submerged permeable structures, Coastal Engineering, 53, 395-417.

Li, T., P. Troch, and J. De Rouck. 2004. Wave overtopping over a sea dike, Journal of Computational Physics, 198, 686-726.

Lin, P., and P.L.F. Liu. 1998. A numerical study of breaking waves in the surf zone, Journal of Fluid Mechanics, 359, 239-264. 
Liu, P.L.F., and K. Al-Banaa. 2004. Solitary wave runup and force on a vertical barrier, Journal of Fluid Mechanics, 505, 225-233.

Losada, I.J., J.L. Lara, R. Guanche, and J.M. Gonzalez-Ondina. 2008. Numerical analysis of wave overtopping of rubble mound breakwaters, Coastal Engineering, 55, 47-62.

Requejo, S., C.Vidal, and I.J. Losada. 2002. Modeling of wave loads and hydraulic performance of vertical permeable structures, Coastal Engineering, 46, 249-276.

Van der Meer, J.W., P. Tönjes, and H. de Waal. 1998. A code for dike height design and examination, Proceedings International Conference on Coastlines, Structures and Breakwaters, Institution of Civil Engineers, Thomas Telford, London, 5-19.

Viccione G., V. Bovolin, and E. Pugliese Carratelli. 2011. Short term variability of pressure distribution on vertical breakwaters using WCSPH, 3rd ECCOMAS Thematic Conference on Computational Methods in Structural Dynamics and Earthquake Engineering (COMPDYN), Corfu, Greece.

Viccione G., V. Bovolin, and E. Pugliese Carratelli. 2012. Simulating fluid-structure interaction with SPH, Tenth International Conference of Numerical Analysis and Applied Mathematics (ICNAAM), Kos, Greece, in press.

Xiang J., J.P. Latham, A.Vire1, E. Anastasakil, C. Painl, and F. Milthaler. 2012. Simulation Tools For Numerical Breakwater Models Including Coupled Fluidity/Y3d Waves, 33rd International Conference on Coastal Engineering, (ICCE), Santander, Spain. 